\title{
One Point Conventional Model to Optimize Trapezoidal Fuzzy Transportation Problem
}

\author{
Dinesh C. S. Bisht \\ Department of Mathematics \\ Jaypee Institute of Information Technology, Noida-201304, India \\ Pankaj Kumar Srivastava \\ Department of Mathematics \\ Jaypee Institute of Information Technology, Noida-201304, India \\ Corresponding author: pankaj.srivastava@jiit.ac.in
}

(Received July 20, 2018; Accepted July 21, 2019)

\begin{abstract}
This article puts forward a new one point approach to optimize trapezoidal fuzzy transportation problem. It proposes the method having point wise breakup of the trapezoidal number in such a way, that fuzzy transportation problem is converted into four crisp transportation problems. The method is equipped with minimum of supply and demand approach. In the end, the solutions are combined to construct the optimal solution. Modified distribution is applied on each crisp problem to develop optimal solution. The scheme presented is compared with competitive methods available in literature and it is found to be in good coordination with these. The scheme is equally good to be applied on unbalanced problems. Two numerical problems are considered to test the performance of the proposed approach.
\end{abstract}

Keywords- One point approach, Trapezoidal fuzzy number, Minimum demand supply, Modified distribution, Fuzzy transportation problem.

\section{Introduction}

An appropriate shipment of commodities from factories to distributers is a crucial step in business management. To deal with this cost-effectively transportation models are developed. A properly modelled transportation problem confirms the well-organized movement of goods. In the transportation modelling, the key task is to decide the way of allocation goods from several origins to several terminuses. The elementary transportation problems were initially established by Hitchcock (1941). In traditional transportation problems, decision makers have a clear idea about the amount of demand, supply and the transportation cost. In the true scenario, decision maker may not have a precise idea about the demand, supply or the cost. These data may be vague because of many affecting factors. In such cases, classical transportation methods are useless. A generalization of classical methods is needed to deal with such type of vagueness. Zadeh (1965) gave a concept to deal with this vagueness by introducing notion of fuzzy sets. This theory is based on grades, where everything is a matter of degree (Bisht et al., 2018; Jain et al., 2018; Srivastava et al., 2018; Bisht and Srivastava, 2019; Srivastava and Bisht, 2019). Since its inception, the theory has given rise to various techniques and concepts to deal with many complex problems (Jain et al., 2017; Goyal and Bisht, 2019).

Bellman and Zadeh (1970) used fuzzy theory in solution of transportation problems. In real life, different type of uncertainty may arise e.g. decisive person may not have correct idea of the transportation cost, or decision maker has a vague idea about the market demands, or there can be ambiguity in the supply of the goods (Kaur and Kumar, 2011; Kumar and Kaur, 2011). To deal 
International Journal of Mathematical, Engineering and Management Sciences

Vol. 4, No. 5, 1251-1263, 2019

https://dx.doi.org/10.33889/IJMEMS.2019.4.5-099

with above cases a more generalized transportation problem solving technique is needed. It can be done by treating the problem as fuzzy transportation problem (FTP) since the decision maker is not clear about the exact inputs (Chhibber et al., 2019).

In FTP, the parameters are represented in fuzzy numbers. It may lead a set of possible optimal solution or fuzzy optimal solution, when decision variables are considered as a fuzzy number. Researchers support the fact for preferring to take fuzzy numbers when decision variables are vague (Buckley and Feuring, 2000; Tanaka et al., 2000; Buckley et al., 2001; Nasrabadi and Nasrabadi, 2004; Dehghan et al. 2006; Allahviranloo et al., 2008; Ghazanfari et al. 2009; Lotfi et al., 2009; Baykasoglu and Gocken, 2012). The FTP is described by special nature of fuzzy numbers (Akyar et al., 2012; Mathur et al., 2016; Bisht and Srivastava, 2017, 2018; Mathur et al., 2018).

Zimmermann (1978) proposed the fuzzy method to solve vector maximization problem, obtained solutions by above presented method found to be more competent. A fuzzy constrained transportation problem is solved to get relationship between settled and fuzzy solution (ÓhÉigeartaigh, 1982). Chanas et al. (1984) presented a fuzzy method using parameters for fuzzy transportation with fuzzy demand and supply. This method gave alternate solution to the problem. Chanas and Kuchta (1996) furnished a technique to get best results of the FTP. The method offered a very useful set of elementary solutions for decision makers. Chanas and Kuchta (1998) solved transportation problem by striking integrality condition on the solution of a problem with fuzzy demand and supply. Saad and Abass (2002) have done a parametric study to the FTPs. Liu and Kao (2004) made advancement to the method on the basis of extension principle. Dinagar and Palanivel (2009) projected fuzzy modified distribution scheme to get the finest fuzzy solutions. Pandian and Natarajan (2010) projected fuzzy zero point technique to find optimal solution to the trapezoidal FTPs. Further, Natarajan (2010) gave a separation scheme for finding a finest solution of interval valued FTPs. Kumar and Kaur (2012) presented a method to deal with unbalanced fuzzy transportation.

In the solution of FTP, defuzzification or fuzzy number ranking is a key task. A proper ranking of fuzzy numbers facilitates appropriate results, at the same time improper ranking can mislead the solutions. Jain (1977) projected a technique based on the concept of maximization set for ranking of the fuzzy numbers. The algebraic operations of crisp numbers are further improved to fuzzy numbers by Dubois and Prade (1978). Yager (1980) projected a technique for the choice of fuzzy subsets on the unit interval based on adjoining to a linear association on interval $[0,1]$. Many authors have explored numerous ranking procedures to yield diverse ranked values for the FTPs (Akyar et al., 2012; Rezvani, 2013; Ganesh and Jayakumar, 2014; Bisht and Srivastava, 2017, 2018; Srivastava and Bisht, 2018, 2019; Mathur and Srivastava, 2019; Nagar et al., 2019).

The central developments of this study are summarized as:

(i) Trapezoidal FTP with fuzzy parameters is considered.

(ii) A point to point method is discussed briefly, which is easy to apply.

(iii) Minimum demand-supply technique is used to get initial basic feasible solution (IBFS).

(iv) Modified distribution (MODI) technique is applied to test the optimality.

(v) A fuzzy optimal solution is produced to give flexibility to the decision makers. 
International Journal of Mathematical, Engineering and Management Sciences

Vol. 4, No. 5, 1251-1263, 2019

https://dx.doi.org/10.33889/IJMEMS.2019.4.5-099

\section{Trapezoidal Fuzzy Number and Corresponding Transportation Problem}

A fuzzy number is characterized by notion of membership function. A number $X^{*}=\left(\mathrm{x}_{1}, \mathrm{x}_{2}, \mathrm{x}_{3}, \mathrm{x}_{4}\right)$ is termed as trapezoidal if its membership function $\mu_{\mathrm{x}^{*}}(\alpha)$ satisfies the condition

$$
\mu_{\mathrm{x}^{*}}(\alpha)=\left\{\begin{array}{cc}
\frac{\alpha-x_{1}}{x_{2}-x_{1}}, & x_{1} \leq \alpha \leq x_{2} \\
1, & x_{2} \leq \alpha \leq x_{3} \\
\frac{\alpha-x_{4}}{x_{3}-x_{4}}, & x_{3} \leq \alpha \leq x_{4} \\
0, & \text { otherwise }
\end{array}\right.
$$

A transportation problem defined in the form of fuzzy trapezoidal number is called trapezoidal FTP. In such FTPs demand, supply and transportation cost will be in terms of fuzzy trapezoidal number. If $\left(\mathrm{c}_{1}, \mathrm{c}_{2}, \mathrm{c}_{3}, \mathrm{c}_{4}\right)$ is the cost of a unit transportation from resource to target then it means the actual transportation cost may vary from $\mathrm{c}_{1}$ to $\mathrm{c}_{4}$ and maximum possibility of cost will be in between $c_{2}$ to $c_{3}$. A similar way of assumption is for supply and demand.

The FTPs may be balanced or unbalanced. The unbalanced problems are made balanced through introduction of dummy rows and dummy columns.

\section{One-Point Conventional Approach Through Minimum of Supply and Demand Algorithm}

The one-point approach is based on the concept of the possible optimized outcome of a FTP if all the four entries of trapezoidal cost with the corresponding demand and supply are covered one by one at a time. It provides all possible optimal transportation costs in appearance of a fuzzy trapezoidal number. This approach is combined with minimum of demand and supply algorithm to solve each crisp transportation problem as described below:

Consider a crisp balanced transportation problem having table of order $(p, r)$ with supply $\mathrm{a}_{\mathrm{i}}, i=1,2, \ldots, p$ and demand $\mathrm{b}_{\mathrm{j}}, j=1,2, \ldots, r$ along with corresponding $\operatorname{cost} \mathrm{c}_{i \mathrm{j}}$. The minimum of demand and supply algorithm is applied through following steps:

Step I: Choose the min $\left(a_{i}, b_{j}\right)$ and then find the lowest cost corresponding to this $\min \left(a_{i}, b_{j}\right)$ value and make allocation. It may have three cases

(i) If min $\left(\mathrm{a}_{\mathrm{i}}, \mathrm{b}_{\mathrm{j}}\right)=\mathrm{a}_{\mathrm{i}}$, allocate $\mathrm{a}_{\mathrm{i}}$ in lowest cost cell of the $i^{\text {th }}$ row and remove this $i^{\text {th }}$ row. It will give a table of order $(p-1) \times$ r. Reduce $b_{j}$ by $b_{j}-a_{i}$ in new transportation problem. 
International Journal of Mathematical, Engineering and Management Sciences

Vol. 4, No. 5, 1251-1263, 2019

https://dx.doi.org/10.33889/IJMEMS.2019.4.5-099

(ii) If min $\left(a_{i}, b_{j}\right)=b_{j}$, allocate $b_{j}$ in lowest cost block of the $\mathrm{j}^{\text {th }}$ column and remove this $\mathrm{j}^{\text {th }}$ column. It will give a table of order $\mathrm{p} x(\mathrm{r}-1)$. Reduce $\mathrm{a}_{\mathrm{i}}$ by $\mathrm{a}_{\mathrm{i}}-\mathrm{b}_{\mathrm{j}}$ in new transportation problem.

(iii)if min $\left(\mathrm{a}_{\mathrm{i}}, \mathrm{b}_{\mathrm{j}}\right)=\mathrm{a}_{\mathrm{i}}=\mathrm{b}_{\mathrm{j}}$, then select the box having lowest cost corresponding to $i^{\text {th }}$ row and $\mathrm{j}^{\text {th }}$ column. Tie in transportation cost will be considered arbitrarily.

Step II: Apply Step I repeatedly till a $1 \times 1$ table is obtained. It will make allocation in all possible cells.

Step III: The IBFS and corresponding cost of transportation acquired through these steps will be $\mathrm{x}_{\mathrm{ij}}$ and $\sum_{\mathrm{i}=1}^{\mathrm{i}=\mathrm{p}} \sum_{\mathrm{j}=1}^{\mathrm{j}=\mathrm{r}} \mathrm{c}_{\mathrm{ij}} x_{i j}$ respectively.

\section{Methodology}

The overall methodology projected in this study comprises following steps to solution of trapezoidal FTPs:

Step 1. A trapezoidal FTP with fuzzy demand, fuzzy supply and fuzzy cost is considered. The parameters are in expressions of trapezoidal fuzzy numbers.

Step 2. Check the FTP for balance.

Step 3. Apply one-point conventional method (discussed in section 3) to get four individual classical transportation problems.

Step 4. Solve crisp transportation problems obtained in step 2 using minimum demand and supply method as described in section 3 , to obtain the IBFS.

Step 5. Apply MODI technique to test the optimality of the crisp solutions in all four problems obtained in step 2.

Step 6. Combine the allocations obtained through point wise calculation of each crisp transportation problem, which gives a trapezoidal fuzzy number as an allocation.

\section{Numerical Illustration}

This section covers two numerical problems to signify the methodology of the proposed algorithm. The first numerical problem represented in Table 1 is directly adopted from Kaur and Kumar (2011) and the results acquired by projected technique are judged against the techniques proposed by Kaur and Kumar (2011) and Mathur et al. (2016). The second numerical problem represented in Table 7 is directly adopted from Ebrahimnejad (2016) and the results acquired by projected technique are judged against the techniques proposed by him. Proposed technique is found in good harmony with these previous techniques. 
International Journal of Mathematical, Engineering and Management Sciences

Vol. 4, No. 5, 1251-1263, 2019

https://dx.doi.org/10.33889/IJMEMS.2019.4.5-099

\subsection{Example 1}

Table 1. FTP in trapezoidal form

\begin{tabular}{|c|c|c|c|c|}
\hline & $\mathrm{R}_{1}$ & $\mathrm{R}_{2}$ & $\mathrm{R}_{3}$ & Supply \\
\hline $\mathrm{A}$ & $(1,4,9,19)$ & $(1,2,5,9)$ & $(2,5,8,18)$ & $(1,5,7,9)$ \\
\hline $\mathrm{B}$ & $(8,9,12,26)$ & $(3,5,8,12)$ & $(7,9,13,28)$ & $(4,7,8,10)$ \\
\hline $\mathrm{C}$ & $(11,12,20,27)$ & $(0,5,10,15)$ & $(4,5,8,11)$ & $(4,5,8,11)$ \\
\hline Demand & $(3,5,8,12)$ & $(4,8,9,10)$ & $(2,4,6,8)$ & \\
\hline
\end{tabular}

\section{Solution:}

\section{First Point Calculation}

The crisp transportation problem obtained from first point value is displayed in Table 2.

Table 2. Transportation cost for first point transportation problem

\begin{tabular}{|c|c|c|c|c|}
\hline & $\mathrm{R}_{1}$ & $\mathrm{R}_{2}$ & $\mathrm{R}_{3}$ & Supply \\
\hline $\mathrm{A}$ & 1 & 1 & 2 & 1 \\
\hline $\mathrm{B}$ & 8 & 3 & 7 & 4 \\
\hline $\mathrm{C}$ & 11 & 0 & 4 & 4 \\
\hline Demand & 3 & 4 & 2 & \\
\hline
\end{tabular}

It's a balanced problem of transportation and applying the minimum of demand-supply algorithm the IBFS is

$$
x_{11}=1, x_{21}=2, x_{22}=2, x_{32}=2, x_{33}=2 \text {. }
$$

The transportation cost against this IBFS will be 31 units.

Applying MODI technique on this IBFS it is confirmed as optimal solution in first iteration.

\section{Second Point Calculation}

The crisp transportation problem obtained from second point value is put on view in Table 3.

Table 3. Transportation cost for second point transportation problem

\begin{tabular}{|c|c|c|c|c|}
\hline & $\mathrm{R}_{1}$ & $\mathrm{R}_{2}$ & $\mathrm{R}_{3}$ & Supply \\
\hline $\mathrm{A}$ & 4 & 2 & 5 & 5 \\
\hline $\mathrm{B}$ & 9 & 5 & 9 & 7 \\
\hline $\mathrm{C}$ & 12 & 5 & 5 & 5 \\
\hline Demand & 5 & 8 & 4 & \\
\hline
\end{tabular}

It's a balanced problem of transportation and applying the minimum of demand-supply algorithm IBFS is

$$
x_{12}=1, x_{13}=4, x_{21}=5, x_{22}=2, x_{32}=5 \text {. }
$$


International Journal of Mathematical, Engineering and Management Sciences

Vol. 4, No. 5, 1251-1263, 2019

https://dx.doi.org/10.33889/IJMEMS.2019.4.5-099

Applying MODI technique on this IBFS the favorable solution is achieved in third iteration. The optimal transportation cost will be 80 units.

\section{Third Point Calculation}

The crisp transportation problem obtained from third point value is displayed in Table 4.

Table 4. Transportation cost for third point transportation problem

\begin{tabular}{|c|c|c|c|c|}
\hline & $\mathrm{R}_{1}$ & $\mathrm{R}_{2}$ & $\mathrm{R}_{3}$ & Supply \\
\hline $\mathrm{A}$ & 9 & 5 & 8 & 7 \\
\hline $\mathrm{B}$ & 12 & 8 & 13 & 8 \\
\hline $\mathrm{C}$ & 20 & 10 & 8 & 8 \\
\hline Demand & 8 & 9 & 6 & \\
\hline
\end{tabular}

It's a balanced problem of transportation and applying the minimum of demand-supply algorithm IBFS is

$$
x_{12}=7, x_{21}=8, x_{22}=0, x_{32}=2, x_{33}=6 \text {. }
$$

Applying MODI technique on this IBFS it is confirmed as optimal solution in first iteration. The corresponding transportation cost will be 199 units.

\section{Fourth Point Calculation}

The crisp transportation problem obtained from fourth point value is presented in Table 5.

Table 5. Transportation cost for fourth point transportation problem

\begin{tabular}{|c|c|c|c|c|}
\hline & $\mathrm{R}_{1}$ & $\mathrm{R}_{2}$ & $\mathrm{R}_{3}$ & Supply \\
\hline $\mathrm{A}$ & 19 & 9 & 18 & 9 \\
\hline $\mathrm{B}$ & 26 & 12 & 28 & 10 \\
\hline $\mathrm{C}$ & 27 & 15 & 11 & 11 \\
\hline Demand & 12 & 10 & 8 & \\
\hline
\end{tabular}

It's a balanced problem of transportation and applying the minimum of demand-supply algorithm IBFS is

$$
x_{11}=2, x_{12}=7, x_{21}=10, x_{32}=3, x_{33}=8 \text {. }
$$

Applying MODI technique on this IBFS it is confirmed as optimal solution in third iteration. The corresponding transportation cost will be 460 units.

\section{Final Allocation}

Finally analyzing the combination of the allocations obtained through point wise calculation of each crisp transportation problem it is concluded that the optimum transportation cost for the FTP will be obtained if the receivers $R_{1}, R_{2}$ and $R_{3}$ receive manufactured goods from dealers $A$ and $B$, from dealers $\mathrm{B}$ and $\mathrm{C}$ and from dealer $\mathrm{C}$ respectively (Table 6) and the corresponding fuzzy transportation cost will be $(31,80,199,460)$ units (Figure 1). 
International Journal of Mathematical, Engineering and Management Sciences

Vol. 4, No. 5, 1251-1263, 2019

https://dx.doi.org/10.33889/IJMEMS.2019.4.5-099

Table 6. Decision table

\begin{tabular}{|c|c|c|c|}
\hline & $\mathrm{R}_{1}$ & $\mathrm{R}_{2}$ & $\mathrm{R}_{3}$ \\
\hline $\mathrm{A}$ & $\checkmark$ & $\times$ & $\times$ \\
\hline $\mathrm{B}$ & $\checkmark$ & $\checkmark$ & $\times$ \\
\hline $\mathrm{C}$ & $\times$ & $\checkmark$ & $\checkmark$ \\
\hline
\end{tabular}

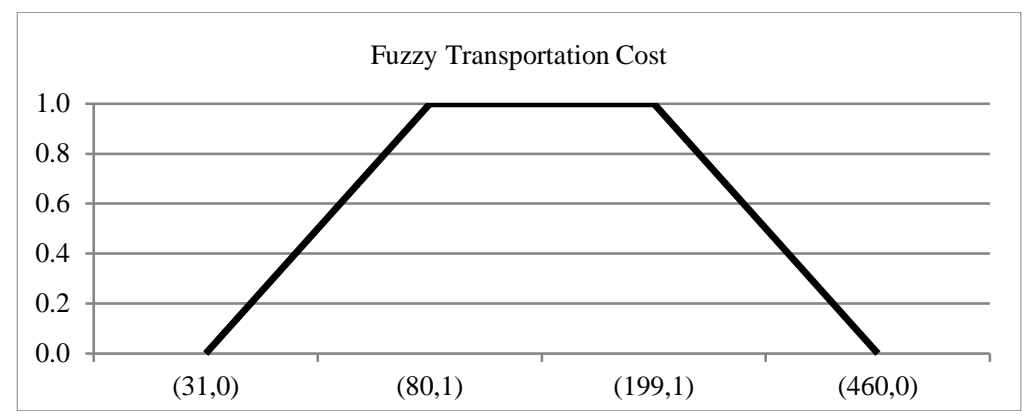

Figure 1. Optimal Fuzzy Transportation Cost

\subsection{Example 2}

Table 7. FTP in trapezoidal form

\begin{tabular}{|c|c|c|c|c|}
\hline & $\mathrm{R}_{1}$ & $\mathrm{R}_{2}$ & $\mathrm{R}_{3}$ & Supply \\
\hline $\mathrm{A}$ & $(10,20,30,40)$ & $(50,60,70,90)$ & $(80,90,110,120)$ & $(70,90,90,100)$ \\
\hline $\mathrm{B}$ & $(60,70,80,90)$ & $(70,80,100,120)$ & $(20,30,50,60)$ & $(40,60,70,80)$ \\
\hline Demand & $(30,40,50,70))$ & $(20,30,40,50)$ & $(40,50,50,80)$ & \\
\hline
\end{tabular}

\section{Solution:}

This is an unbalanced FTP, so making it balanced it becomes as described in Table 8.

Table 8 . Balanced form of example 2

\begin{tabular}{|c|c|c|c|c|c|}
\hline & $\mathrm{R}_{1}$ & $\mathrm{R}_{2}$ & $\mathrm{R}_{3}$ & Dummy & Supply \\
\hline A & $(10,20,30,40)$ & $(50,60,70,90)$ & $(80,90,110,120)$ & $(0,0,0,0)$ & $(70,90,90,100)$ \\
\hline B & $(60,70,80,90)$ & $(70,80,100,120)$ & $(20,30,50,60)$ & $(0,0,0,0)$ & $(40,60,70,80)$ \\
\hline Dummy & $(0,0,0,0)$ & $(0,0,0,0)$ & $(0,0,0,0)$ & $(0,0,0,0)$ & $(0,0,10,50)$ \\
\hline Demand & $(30,40,50,70)$ & $(20,30,40,50)$ & $(40,50,50,80)$ & $(20,30,30,30)$ & \\
\hline
\end{tabular}

\section{First Point Calculation}

The crisp transportation problem obtained from first point value is displayed in Table 9. 
International Journal of Mathematical, Engineering and Management Sciences

Vol. 4, No. 5, 1251-1263, 2019

https://dx.doi.org/10.33889/IJMEMS.2019.4.5-099

Table 9. Transportation cost for first point transportation problem

\begin{tabular}{|c|c|c|c|c|c|}
\hline & $\mathrm{R}_{1}$ & $\mathrm{R}_{2}$ & $\mathrm{R}_{3}$ & Dummy & Supply \\
\hline $\mathrm{A}$ & 10 & 50 & 80 & 0 & 70 \\
\hline $\mathrm{B}$ & 60 & 70 & 20 & 0 & 40 \\
\hline Dummy & 0 & 0 & 0 & 0 & 0 \\
\hline Demand & 30 & 20 & 40 & 20 & \\
\hline
\end{tabular}

It's a balanced problem of transportation and applying the minimum of demand-supply algorithm IBFS is

$$
x_{11}=30, x_{12}=20, x_{14}=20, x_{23}=40, x_{31}=0, x_{32}=0 \text {. }
$$

Applying MODI technique on this IBFS it is confirmed as optimal solution in second iteration. The corresponding transportation cost will be 2100 units.

\section{Second Point Calculation}

The crisp transportation problem obtained from second point value is put on view in Table 10.

Table 10. Transportation cost for second point transportation problem

\begin{tabular}{|c|c|c|c|c|c|}
\hline & $\mathrm{R}_{1}$ & $\mathrm{R}_{2}$ & $\mathrm{R}_{3}$ & Dummy & Supply \\
\hline $\mathrm{A}$ & 20 & 60 & 90 & 0 & 90 \\
\hline $\mathrm{B}$ & 70 & 80 & 30 & 0 & 60 \\
\hline Dummy & 0 & 0 & 0 & 0 & 0 \\
\hline Demand & 40 & 30 & 50 & 30 & \\
\hline
\end{tabular}

It's a balanced problem of transportation and applying the minimum of demand-supply algorithm IBFS is

$$
x_{11}=40, x_{12}=30, x_{13}=20, x_{23}=30, x_{24}=30, x_{33}=0 \text {. }
$$

Applying MODI technique on this IBFS it the favorable solution is achieved in second iteration. The optimal transportation cost will be 4100 units.

\section{Third Point Calculation}

The crisp transportation problem obtained from third point value is displayed in Table 11.

Table 11. Transportation cost for third point transportation problem

\begin{tabular}{|c|c|c|c|c|c|}
\hline & $\mathrm{R}_{1}$ & $\mathrm{R}_{2}$ & $\mathrm{R}_{3}$ & Dummy & Supply \\
\hline $\mathrm{A}$ & 30 & 70 & 110 & 0 & 90 \\
\hline $\mathrm{B}$ & 80 & 100 & 50 & 0 & 70 \\
\hline Dummy & 0 & 0 & 0 & 0 & 10 \\
\hline Demand & 50 & 40 & 50 & 30 & \\
\hline
\end{tabular}

It's a balanced problem of transportation and applying the minimum of demand-supply algorithm IBFS is

$$
x_{11}=30, x_{12}=30, x_{14}=30, x_{21}=20, x_{23}=50, x_{32}=10 \text {. }
$$


International Journal of Mathematical, Engineering and Management Sciences

Vol. 4, No. 5, 1251-1263, 2019

https://dx.doi.org/10.33889/IJMEMS.2019.4.5-099

Applying MODI technique on this IBFS it is confirmed as optimal solution in second iteration. The corresponding transportation cost will be 6100 units.

\section{Fourth Point Calculation}

The crisp transportation problem obtained from fourth point value is put on view in Table 12 .

Table 12. Transportation cost for fourth point transportation problem

\begin{tabular}{|c|c|c|c|c|c|}
\hline & $\mathrm{R}_{1}$ & $\mathrm{R}_{2}$ & $\mathrm{R}_{3}$ & Dummy & Supply \\
\hline $\mathrm{A}$ & 40 & 90 & 120 & 0 & 100 \\
\hline $\mathrm{B}$ & 90 & 120 & 60 & 0 & 80 \\
\hline Dummy & 0 & 0 & 0 & 0 & 50 \\
\hline Demand & 70 & 50 & 80 & 30 & \\
\hline
\end{tabular}

It's a balanced problem of transportation and applying the minimum of demand-supply algorithm IBFS is

$$
x_{11}=50, x_{12}=50, x_{23}=50, x_{24}=30, x_{31}=20, x_{33}=30 \text {. }
$$

Applying MODI technique on this IBFS it is confirmed as optimal solution in third iteration. The corresponding transportation cost will be 7600 units.

\section{Final Allocation}

Considering the combination of the allocations it is concluded that the optimum transportation cost for the FTP will be obtained if the receivers $R_{1}$ and $R_{2}$ receive product from supplier $A$ and $R_{3}$ receives product from supplier $B$ only (Table 13) and the corresponding fuzzy transportation cost will be (2100, 4100, 6100, 7600) units (Figure 2).

Table 13. Decision table

\begin{tabular}{|c|c|c|c|c|}
\hline & $\mathrm{R}_{1}$ & $\mathrm{R}_{2}$ & $\mathrm{R}_{3}$ & Dummy Destination \\
\hline $\mathrm{A}$ & $\checkmark$ & $\checkmark$ & $\times$ & $\checkmark$ \\
\hline $\mathrm{B}$ & $\times$ & $\times$ & $\times$ & $\times$ \\
\hline $\begin{array}{c}\text { Dummy } \\
\text { Source }\end{array}$ & $\times$ & $\times$ & $\times$ & $\times$ \\
\hline
\end{tabular}

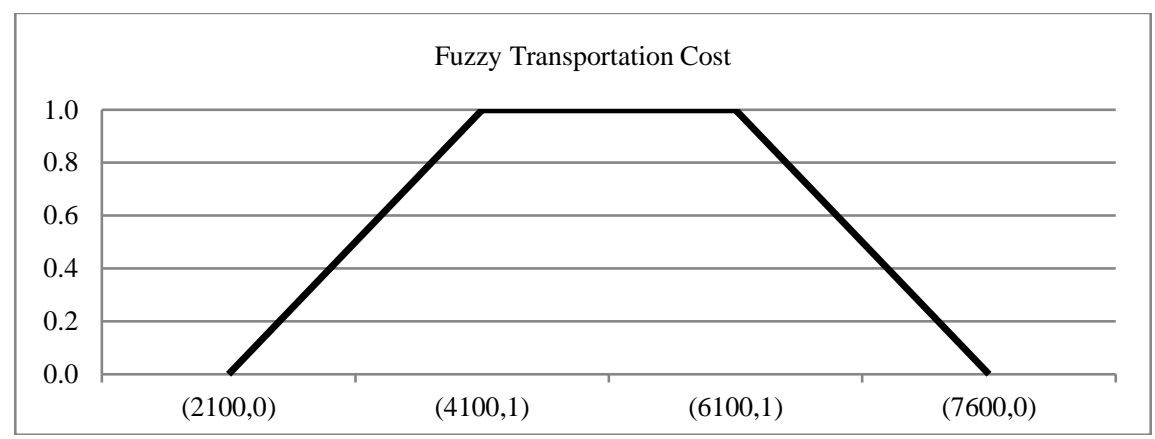

Figure 2. Optimal Fuzzy transportation cost 
International Journal of Mathematical, Engineering and Management Sciences

Vol. 4, No. 5, 1251-1263, 2019

https://dx.doi.org/10.33889/IJMEMS.2019.4.5-099

\section{Comparative Study}

Both the real life examples 1 and 2 under consideration are compared with other existing methods for the problem and comparison of allocation is depicted in Table 14 and 15. The proposed algorithm either provides better alternating solution or verifies the result.

Table 14. Comparative study of Example 1

\begin{tabular}{|c|c|c|c|c|c|c|c|c|c|}
\hline & \multicolumn{3}{|c|}{$\mathrm{R}_{1}$} & \multicolumn{3}{|c|}{$\mathrm{R}_{2}$} & \multicolumn{3}{|c|}{$\mathrm{R}_{3}$} \\
\hline & 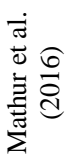 & 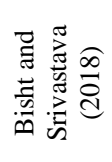 & 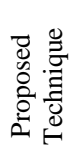 & 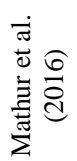 & 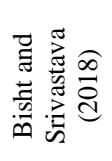 & 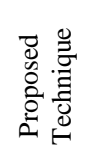 & 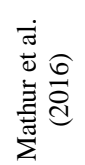 & 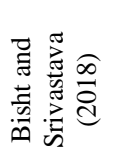 & 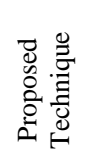 \\
\hline A & $\checkmark$ & $\checkmark$ & $\checkmark$ & $\checkmark$ & $x$ & $x$ & $x$ & $x$ & $x$ \\
\hline B & $\checkmark$ & $\checkmark$ & $\checkmark$ & $x$ & $\checkmark$ & $\checkmark$ & $x$ & $x$ & $x$ \\
\hline $\mathrm{C}$ & $x$ & $x$ & $x$ & $\checkmark$ & $\checkmark$ & $\checkmark$ & $\checkmark$ & $\checkmark$ & $\checkmark$ \\
\hline
\end{tabular}

Table 15. Comparative study of Example 2

\begin{tabular}{|c|c|c|c|c|c|c|}
\hline & \multicolumn{2}{|c|}{$\mathbf{R}_{1}$} & \multicolumn{2}{|c|}{$\mathbf{R}_{\mathbf{2}}$} & \multicolumn{2}{|c|}{$\mathbf{R}_{3}$} \\
\hline & 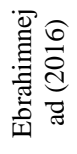 & 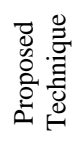 & 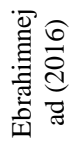 & 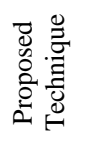 & 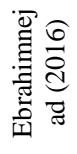 & 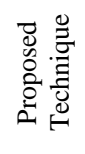 \\
\hline $\mathbf{A}$ & $\checkmark$ & $\checkmark$ & $\checkmark$ & $x$ & $x$ & $x$ \\
\hline B & $\checkmark$ & $\checkmark$ & $x$ & $\checkmark$ & $x$ & $x$ \\
\hline C & $x$ & $x$ & $\checkmark$ & $\checkmark$ & $\checkmark$ & $\checkmark$ \\
\hline
\end{tabular}

\section{Conclusion}

This research article deals with an effortless and robust method to solve FTPs with trapezoidal fuzzy parameters. A point to point method is applied to get classical transportation problems out of FTP. Further minimum demand and supply method followed by MODI technique is used to get IBFS and optimal solution of crisp problems respectively. Hence obtained solutions of all four problems are clubbed to give a trapezoidal fuzzy solution. This fuzzy solution gives a flexibility to decision maker on particular decision. Two distinct types of the FTPs are discussed: one with balanced fuzzy transportation data and the other with un-balanced fuzzy transportation data. It is 
International Journal of Mathematical, Engineering and Management Sciences

Vol. 4, No. 5, 1251-1263, 2019

https://dx.doi.org/10.33889/IJMEMS.2019.4.5-099

found that this method is equally applicable on both types of problems. Results obtained by presented procedure are matched up to the existing methods. The proposed scheme is got to be more operative to solve such FTPs having data in trapezoidal fuzzy form. The final transportation cost is articulated by fuzzy number in place of crisp value, more flexible decisions can be carried out. This technique proposes noteworthy engineering and industrial relevance in decision making.

\section{Conflict of Interest}

Both authors have contributed equally in this work. The authors declare that there is no conflict of interest for this publication.

\section{Acknowledgement}

The authors extend their appreciation to the anonymous reviewers for their valuable suggestions.

\section{References}

Akyar, E., Akyar, H., \& Düzce, S.A. (2012). A new method for ranking triangular fuzzy numbers. International Journal of Uncertainty, Fuzziness and Knowledge-Based Systems, 20(05), 729-740.

Allahviranloo, T., Lotfi, F.H., Kiasary, M.K., Kiani, N.A., \& Alizadeh, L. (2008). Solving fully fuzzy linear programming problem by the ranking function. Applied Mathematical Sciences, 2(1), 19-32.

Baykasoglu, A., \& Gocken, T. (2012). A direct solution approach to fuzzy mathematical programs with fuzzy decision variables. Expert Systems with Applications, 39(2), 1972-1978.

Bellman, R.E., \& Zadeh, L.A. (1970). Decision-making in a fuzzy environment. Management Science, $17(4), \mathrm{B}-141$.

Bisht, D., \& Srivastava, P.K. (2017, October). A unique conversion approach clubbed with a new ranking technique to optimize fuzzy transportation cost. In AIP Conference Proceedings, 1897(1), p. 020023. AIP Publishing.

Bisht, D.C.S., \& Srivastava, P.K. (2018). Trisectional fuzzy trapezoidal approach to optimize interval data based transportation problem. Journal of King Saud University-Science (in press).

Bisht, D.C.S., \& Srivastava, P.K. (2019). Fuzzy optimization and decision making. In Advanced Fuzzy Logic Approaches in Engineering Science, pp. 310-326. IGI Global.

Bisht, D.C.S, Srivastava, P.K., \& Ram, M. (2018). Role of fuzzy logic in flexible manufacturing system. In Diagnostic Techniques in Industrial Engineering, (pp. 233-243). Springer, Cham.

Buckley, J.J., \& Feuring, T. (2000). Evolutionary algorithm solution to fuzzy problems: fuzzy linear programming. Fuzzy Sets and Systems, 109(1), 35-53.

Buckley, J.J., Feuring, T., \& Hayashi, Y. (2001). Multi-objective fully fuzzified linear progamming. International Journal of Uncertainty, Fuzziness and Knowledge-Based Systems, 9(05), 605-621.

Chanas, S., \& Kuchta, D. (1996). A concept of the optimal solution of the transportation problem with fuzzy cost coefficients. Fuzzy Sets and Systems, 82(3), 299-305.

Chanas, S., \& Kuchta, D. (1998). Fuzzy integer transportation problem. Fuzzy Sets and Systems, 98(3), 291-298. 
International Journal of Mathematical, Engineering and Management Sciences

Vol. 4, No. 5, 1251-1263, 2019

https://dx.doi.org/10.33889/IJMEMS.2019.4.5-099

Chanas, S., Kołodziejczyk, W., \& Machaj, A. (1984). A fuzzy approach to the transportation problem. Fuzzy Sets and Systems, 13(3), 211-221.

Chhibber, D., Bisht, D.C.S., \& Srivastava, P.K. (2019, January). Ranking approach based on incenter in triangle of centroids to solve type-1 and type-2 fuzzy transportation problem. In AIP Conference Proceedings, 2061(1), p. 020022. AIP Publishing.

Dehghan, M., Hashemi, B., \& Ghatee, M. (2006). Computational methods for solving fully fuzzy linear systems. Applied Mathematics and Computation, 179(1), 328-343.

Dinagar, D.S., \& Palanivel, K. (2009). The transportation problem in fuzzy environment. International Journal of Algorithms, Computing and Mathematics, 2(3), 65-71.

Dubois, D., \& Prade, H. (1978). Operations on fuzzy numbers. International Journal of Systems Science, 9(6), 613-626.

Ebrahimnejad, A. (2016). New method for solving fuzzy transportation problems with LR flat fuzzy numbers. Information Sciences, 357, 108-124.

Ganesh, A.H., \& Jayakumar, S. (2014). Ranking of fuzzy numbers using radius of gyration of centroids. International Journal of Basic and Applied Sciences, 3(1), 17-22.

Ghazanfari, M., Yousefli, A., Ameli, M.S.J., \& Bozorgi-Amiri, A. (2009). A new approach to solve timecost trade-off problem with fuzzy decision variables. The International Journal of Advanced Manufacturing Technology, 42(3-4), 408-414.

Goyal, G., \& Bisht, D.C.S. (2019, January). An aggregated higher order fuzzy logical relationships technique. In AIP Conference Proceedings, 2061(1), p. 020023. AIP Publishing.

Hitchcock, F.L. (1941). The distribution of a product from several sources to numerous localities. Studies in Applied Mathematics, 20(1-4), 224-230.

Jain, R. (1977). A procedure for multiple-aspect decision making using fuzzy sets. International Journal of Systems Science, 8(1), 1-7.

Jain, S., Bisht, D.C.S., \& Mathpal, P.C. (2018). Particle swarm optimised fuzzy method for prediction of water table elevation fluctuation. International Journal of Data Analysis Techniques and Strategies, 10(2), 99-110.

Jain, S., Bisht, D.C.S., Singh, P., \& Mathpal, P.C. (2017, October). Real coded genetic algorithm for fuzzy time series prediction. In AIP Conference Proceedings, 1897(1), p. 020021. AIP Publishing.

Jain, S., Mathpal, P.C., Bisht, D., \& Singh, P. (2018). A unique computational method for constructing intervals in fuzzy time series forecasting. Cybernetics and Information Technologies, 18(1), 3-10.

Kaur, A., \& Kumar, A. (2011). A new method for solving fuzzy transportation problems using ranking function. Applied Mathematical Modelling, 35(12), 5652-5661.

Kumar, A., \& Kaur, A. (2011). Application of classical transportation methods for solving fuzzy transportation problems. Journal of Transportation Systems Engineering and Information Technology, $11(5), 68-80$.

Kumar, A., \& Kaur, A. (2012). Methods for solving unbalanced fuzzy transportation problems. Operational Research, 12(3), 287-316.

Liu, S.-T., \& Kao, C. (2004). Solving fuzzy transportation problems based on extension principle. European Journal of Operational Research, 153(3), 661-674.

Lotfi, F.H., Allahviranloo, T., Jondabeh, M.A., \& Alizadeh, L. (2009). Solving a full fuzzy linear programming using lexicography method and fuzzy approximate solution. Applied Mathematical Modelling, 33(7), 3151-3156. 
International Journal of Mathematical, Engineering and Management Sciences

Vol. 4, No. 5, 1251-1263, 2019

https://dx.doi.org/10.33889/IJMEMS.2019.4.5-099

Mathur, N., \& Srivastava, P.K. (2019, January). A pioneer optimization approach for hexagonal fuzzy transportation problem. In AIP Conference Proceedings, 2061(1), p. 020030. AIP Publishing.

Mathur, N., Srivastava, P.K., \& Paul, A. (2016). Trapezoidal fuzzy model to optimize transportation problem. International Journal of Modeling, Simulation, and Scientific Computing, 7(03), 1650028.

Mathur, N., Srivastava, P.K., \& Paul, A. (2018). Algorithms for solving fuzzy transportation problem. International Journal of Mathematics in Operational Research, 12(2), 190-219.

Nagar, P., Srivastava, A., \& Srivastava, P.K. (2019). Optimization of species transportation via an exclusive fuzzy trapezoidal centroid approach. Mathematics in Engineering, Science and Aerospace, 10(2), 271-280.

Nasrabadi, M.M., \& Nasrabadi, E. (2004). A mathematical-programming approach to fuzzy linear regression analysis. Applied Mathematics and Computation, 155(3), 873-881.

Natarajan, P.P.G. (2010). A new method for finding an optimal solution of fully interval integer transportation problems. Applied Mathematical Sciences, 4(37), 1819-1830.

ÓhÉigeartaigh, M. (1982). A fuzzy transportation algorithm. Fuzzy Sets and Systems, 8(3), 235-243.

Pandian, P., \& Natarajan, G. (2010). A new algorithm for finding a fuzzy optimal solution for fuzzy transportation problems. Applied Mathematical Sciences, 4(2), 79-90.

Rezvani, S. (2013). Ranking generalized trapezoidal fuzzy numbers with Euclidean distance by the incentre of centroids. Mathematica Aeterna, 3(2), 103-114.

Saad, O.M., \& Abass, S.A. (2002). A parametric study on transportation problem under fuzzy environment. Engineering Journal of University of Qatar, 15, 165-176.

Srivastava, P. K., Bisht, D., \& Ram, M. (2018). Soft computing techniques and applications. In Advanced Mathematical Techniques in Engineering Sciences, pp. 57-69. Taylor \& Francis Group.

Srivastava, P.K., \& Bisht, D.C.S. (2018). Dichotomized incenter fuzzy triangular ranking approach to optimize interval data based transportation problem. Cybernetics and Information Technologies, 18(4), 111-119.

Srivastava, P.K., \& Bisht, D.C.S. (2019). An efficient fuzzy minimum demand supply approach to solve fully fuzzy transportation problem. Mathematics in Engineering, Science and Aerospace, 10(2), 253269.

Srivastava, P.K., \& Bisht, D.C.S. (2019). Recent trends and applications of fuzzy logic. In Advanced Fuzzy Logic Approaches in Engineering Science (pp. 327-340). IGI Global.

Tanaka, H., Guo, P., \& Zimmermann, H.-J. (2000). Possibility distributions of fuzzy decision variables obtained from possibilistic linear programming problems. Fuzzy Sets and Systems, 113(2), 323-332.

Yager, R.R. (1980). On choosing between fuzzy subsets. Kybernetes, 9(2), 151-154.

Zadeh, L.A. (1965). Fuzzy sets. Information and Control, 8(3), 338-353.

Zimmermann, H.-J. (1978). Fuzzy programming and linear programming with several objective functions. Fuzzy Sets and Systems, 1(1), 45-55. 